clinical state became serious with lethargy, aspontaneity, disinhibition and executive dysfunction.

Biological features were abnormal with elevated creatinine phosphokinase (3415 UI/l), increased C-reactive protein $(3.7 \mathrm{mg} /$ dl) and hepatic cytolysis. Her treatment consisted of cyclophosphamide and methylprednisolone, and the introduction of a titrating-dose (up to $600 \mathrm{mg}$ ) of quetiapine for the psychiatric symptoms was decided upon. Her creatinine phosphokinase levels returned progressively to normal, and no signs of neuroleptic malignant syndrome were observed. Six weeks after continuing this treatment, biological and clinical features were normalised.

This case illustrates the importance of differentiating delirium caused by a neuropsychiatric systemic lupus erythematosus, a steroid-induced delirium $^{1}$ (which was not the case here as the patient had not been receiving any steroids when she developed the second psychotic episode) and an alteration in the consciousness level due to neuroleptic malignant syndrome, which was the case here.

Although there are no guidelines for the treatment of the psychiatric manifestations of systemic lupus erythematosus, it usually includes immunosuppressants associated with secondgeneration antipsychotics. ${ }^{3}$ The diagnosis of neuroleptic malignant syndrome is based on muscle rigidity, hyperthermia, delirium and autonomic disturbances. ${ }^{4}$ The dopaminergic hypothesis of the syndrome is well documented. ${ }^{5}$ Neuroleptic malignant syndrome is not an absolute contraindication for further antipsychotic treatment and some factors can reduce that risk: avoiding the long-term use of antipsychotics, using low-potency agents, adjunctive treatments and slow titration. ${ }^{2}$

In this case, we suggest that the introduction of quetiapine - a lower $\mathrm{D}_{2}$-affinity antipsychotic - was an interesting alternative.

1 Brey RL, Holliday SL, Saklad AR, Navarrete MG, Hermosillo-Romo D, Stallworth CL, Valdez CR, Escalante A, del Rincón I, Gronseth G, Rhine CB, Padilla P, McGlasson D. Neuropsychiatric syndromes in lupus: prevalence using standardized definitions. Neurology 2002; 58: 1214-20.

2 Haddad PM, Dursun SM. Neurological complications of psychiatric drugs: clinical features and management. Hum Psychopharmacol Clin Exp 2008; 23 15-26.

3 Stojanovich L, Zandman-Goddard G, Pavlovich S, Sikanich N. Psychiatric manifestations in systemic lupus erythematosus. Autoimmunity Rev 2007; 6 : 421-6.

4 Ananth J, Parameswaran S, Gunatilake S, Burgoyne K, Sidhom T. Neuroleptic malignant ayndrome and atypical antipsychotic drugs. J Clin Psychiatry 2004; 65: 464-70.

5 Strawn JR, Keck PE Jr, Caroff SN. Neuroleptic malignant syndrome. Am J Psychiatry 2007; 164: 870-6.

Philippe Verdoot, MD, Eric L. Constant, MD, PhD and Arlette Seghers, MD Université Catholique de Louvain, Cliniques Universitaires Saint Luc, Adult Psychiatric Unit, Belgium. Email: philippe.verdoot@uclouvain.be

doi: $10.1192 /$ bjp.193.6.507a

\section{Are antidepressants safe during pregnancy?}

Ramos et $a l^{1}$ report that the use of antidepressant medications by women during the first trimester of pregnancy is not associated with an increased risk for major congenital malformations in children. The authors have a good database to study this topic but have described and analysed it using a case-control framework. They assembled two cohorts, with and without exposure to antidepressants during pregnancy. They then observed the various outcomes in both groups. We calculated the relative risk (RR) for major congenital malformations following use of antidepressants during first trimester of pregnancy as 1.13 (95\% CI 0.86-1.48) from their published data. Estimating such relative risk and population attributable risk $(5.76 \%)$ would have bolstered their arguments, as a cohort design is superior to a case-control strategy.

However, we suggest caution in generalising these findings because of two important limitations that were not acknowledged in their paper. If antidepressants are associated with more spontaneous abortions and an increased number of minor congenital anomalies, their lack of association with major congenital anomalies will not imply safety. A previous meta-analysis of 3567 women established a significantly increased RR of 1.45 (95\% CI 1.19-1.77) for spontaneous abortions following use of antidepressants during pregnancy. ${ }^{2}$ Individual antidepressants such as selective serotonin reuptake inhibitors ${ }^{3}$ and other newer antidepressants $^{4,5}$ have led to more miscarriages when compared with unexposed control groups. As Ramos et al have included exclusively women who had their pregnancies ending in delivery, they do not add any information regarding spontaneous abortions.

In another study of 482 pregnant women, ${ }^{6}$ fluoxetine caused significantly more prematurity $(\mathrm{RR}=4.8,95 \% \mathrm{CI} 1.1-20.8)$, more admissions to special care nurseries ( $\mathrm{RR}=2.6,95 \% \mathrm{CI} 1.1-6.9)$ and worse neonatal adaptation ( $\mathrm{RR}=8.7,95 \%$ CI 2.9-26.6) after adjusting for all potential confounders. A total of $15.5 \%$ of infants exposed to fluoxetine had three or more minor congenital anomalies compared with $6.5 \%$ of infants who were not exposed to fluoxetine $(P=0.03) .{ }^{6}$ However, Ramos et al excluded minor congenital anomalies during case ascertainment without any explicit justification. Absence of association between use of antidepressants and major congenital malformations will not make a clinician confident to continue antidepressants during the first trimester of pregnancy if there are concerns over spontaneous abortions, prematurity and minor congenital anomalies. Hence, we encourage cautious interpretation of these findings as well as judicious use of antidepressants for women of reproductive age.

1 Ramos $E$, St-André $M$, Rey E, Oraichi $D$, Bérard A. Duration of antidepressant use during pregnancy and risk of major congenital malformations. $\mathrm{Br} J$ Psychiatry 2008; 192: 344-50.

2 Hemels ME, Einarson A, Koren G, Lanctôt KL, Einarson TR. Antidepressant use during pregnancy and the rates of spontaneous abortions: a metaanalysis. Ann Pharmacother 2005; 39: 803-9.

3 Pastuszak A, Schick-Boschetto B, Zuber C, Feldkamp M, Pinelli M, Sinn S, Donnenfeld $\mathrm{A}$, McCormack $\mathrm{M}$, Leen-Mitchell $\mathrm{M}$, Woodland $\mathrm{C}$. Pregnancy outcome following first-trimester exposure to fluoxetine (Prozac). JAMA 1993; 269: 2246-8.

4 Djulus J, Koren G, Einarson TR, Wilton L, Shakir S, Diav-Citrin O, Kennedy D, Voyer Lavigne S, De Santis M, Einarson A. Exposure to mirtazapine during pregnancy: a prospective, comparative study of birth outcomes. J Clin Psychiatry 2006; 67: 1280-4.

5 Chun-Fai-Chan B, Koren G, Fayez I, Kalra S, Voyer-Lavigne S, Boshier A, Shakir S, Einarson A. Pregnancy outcome of women exposed to bupropion during pregnancy: a prospective comparative study. Am J Obstet Gynecol 2005; 192: 932-6.

6 Chambers $\mathrm{C}$, Johnson K, Dick L, Felix R, Jones KL. Birth outcomes in pregnant women taking fluoxetine. N Engl J Med 1996; 335: 1010-5.

Anto P. Rajkumar, K. S. Jacob, Department of Psychiatry, Christian Medical College, Vellore-632002, India. Email: antoprajkumar@cmcvellore.ac.in

doi: 10.1192/bjp.193.6.508

Authors' reply: The nested case-control approach that we used is the most effective design to study rare outcomes such as major congenital malformations. ${ }^{1,2}$ This is even truer since it was performed in a well-established cohort of women with pre-pregnancy diagnosed psychiatric disorders. We disagree with Rajkumar \& Jacob that a cohort approach would have been better, based on the fact that it lacks power for research in perinatal pharmacoepidemiology. This was clearly apparent when several small human cohort studies published in the 1990s did not suggest 